\title{
Prevalence of Melophagus ovinus and Bovicola ovis infestation in sheep in Wogera District, North Gondar Zone, Ethiopia
}

\author{
Amare Eshetu*, Tilahun Ayele, Shimelis Mengistu, and Dinaol Belina
}

College of Veterinary Medicine, Haramaya University, PO Box-138, Dire Dawa, Ethiopia

\begin{abstract}
The study was conducted from October, 2015 to May, 2016 in Wogera district, North Gondar zone, Ethiopia with the objectives of identifying and estimating the prevalence of sheep ked and lice infestation and to appraise potential risk factors of their attachment to sheep. Out of 423 sheep examined $71.6 \%$ were infested either by Melophagus ovinus (M. ovinus) or Bovicola ovis (B. ovis) or both. The prevalence of $M$. ovinus and B. ovis was $33.57 \%$ and $12.07 \%$ respectively. Mixed infestation of $M$. ovinus and $B$. ovis $(25.53 \%)$ was also recorded. The overall prevalence of $M$. ovinus and $B$. ovis infestation was significantly varied among the age $\left(X^{2}=56.52 ; P=0.00\right), \operatorname{sex}\left(X^{2}=14.71 ; P=0.00\right)$ and body condition $\left(X^{2}=22.52 ; P=0.00\right)$ categories of sheep. The prevalence of $M$. ovinus in sheep of poor $(70.1 \%)$ and medium (64.5\%) body condition was significantly $\left(X^{2}=23.29 ; P=0.00\right)$ higher as compared to those of good body $(40.5 \%)$ condition. Furthermore, the prevalence of $M$. ovinus was significantly varied with age $\left(X^{2}=99.26 ; P=0.00\right)$. Similarly, $B$. ovis prevalence was significantly $\left(X^{2}=16.56 ; P=0.00\right)$ highest in poor $(52.9 \%)$ and medium $(38.2 \%)$ than in good $(25 \%)$ body condition score group. Moreover, the prevalence of $B$. ovis was significantly $\left(X^{2}=7.44 ; P=0.008\right)$ higher in rams $(46.5 \%)$ than in ewes $(33 \%)$ but, did not significantly varied with age $(p>0.05)$. Significant differences were noted in harboring mixed $B$. ovis and $M$. ovinus infestations among the age $\left(X^{2}=23.42 ; P=0.00\right)$, sex $\left(X^{2}=18.41\right.$; $\mathrm{P}=0.00)$ and body condition $\left(X^{2}=21.74 ; P=0.00\right)$ groups. In conclusion, further studies on prevalence and economic impacts of infestation of sheep with $M$. ovinus and $B$. ovis are recommended.
\end{abstract}

Keywords: Bovicola ovis; Ethiopia; Ectoparasites; Melophagus ovinus; Sheep

\section{Introduction}

In Ethiopia nearly 25.5 million sheep are reared in varied agroecologies and production systems for multiple purposes such as meat production, income generation, and as a source of skin [1,2]; contributing significantly to small scale farmers' livelihoods [3]. Contribution from sheep production to Ethiopian economy is adversely affected by several constraints. The subclinical parasitism due to endoparasites and ectoparasitism form the main factors [4]. Ectoparasites are however being more important in the changing scenario as they have a range of direct and indirect consequences on their hosts [5]. Ked and lice of small ruminant feeds on the blood of their hosts thus cause blood loss leading to anaemia [6]. They cause irritation to the skin and stimulate scratching, rubbing, and licking leading to restlessness, damage to the fleece and skin and reduction in carcass weight [6,7]. Furthermore, Ked and lice of sheep cause downgrading and rejection of sheep skins [8] thus, adversely affect productivity and reproductive efficiency. Ectoparasites are also vector for various diseases [9]. Furthermore, ectoparasites have major impact on welfare of their hosts [10]. In general, external parasitism adversely affect economic production of sheep resulting in poor sheep products particularly skins thus causes huge losses in terms of income to producers, the skin processing and export industries and the country at large $[7,11,12]$.

Ethiopia used to get the second largest foreign currency earnings from the export of skins and hides which has been deteriorating due to the decrease in skin quality owing to the increase in external parasite infestations [11]. Annually, sheep skin contributes about $30 \%$ of skins and hides production based on off take rate [7]. However, studies in the country indicated that ectoparasites are becoming growing threat for small ruminant production and export of skin in Ethiopia and it has been reported that about $35 \%$ of sheep skin rejections in the country are due to external parasitism $[12,13]$. Both lice and ked are considered as a cause of 'ekek' in Ethiopian sheep skins thus, play a major role in the continuous declining in quality of skin of small ruminants including sheep [14].

In Ethiopia national control program against ectoparasites and skin diseases have been designed by the Ministry of Agriculture and Rural Development of Ethiopia in 2005 and launched in Tigray, Amhara and Afar regions [15]. Regardless of which, reports from different parts of country indicated that ectoparasitism of sheep is still alarming condition $[4,7,12,16,17]$. Additionally, to the best of our understanding, all the earlier reports on ked and lice of sheep in Ethiopia originated from studies of other ectoparasites, especially ticks and mites or based on examination of fresh sheep skins after slaughter. Therefore, the objectives of this study were to identify and estimate the prevalence of sheep ked and lice infestations in their hosts' natural environment and to appraise potential risk factors of their attachment to sheep in Wogera District, North Gondar Zone, Ethiopia.

\section{Materials and Methods}

\section{Study area}

The present study was conducted from October, 2015 to May, 2016 in Wogera district, located between $37.36^{\circ}$ East and $12.46^{\circ}$ North longitude and at an altitude of $2900 \mathrm{~m}$. a. s. 1 in the North Gondar zone highlands, $781 \mathrm{~km}$ from Addis Ababa and $41 \mathrm{~km}$ from Gondar town in

${ }^{*}$ Corresponding author: Amare Eshetu, College of Veterinary Medicine, Haramaya University PO Box-138, Dire Dawa, Ethiopia, Tel: 6540332; E-mail: amare.eshetu@yahoo.com

Received April 13, 2017; Accepted April 27, 2017; Published April 28, 2017

Citation: Eshetu A, Ayele T, Mengistu S, Belina D (2017) Prevalence of Melophagus ovinus and Bovicola ovis infestation in sheep in Wogera District, North Gondar Zone, Ethiopia. J Vet Sci Technol 8: 440. doi: 10.4172/2157-7579.1000440

Copyright: $\odot 2017$ Eshetu A, et al. This is an open-access article distributed under the terms of the Creative Commons Attribution License, which permits unrestricted use, distribution, and reproduction in any medium, provided the original author and source are credited. 
Amhara National Regional State, Ethiopia. It has annual average rainfall of $700 \mathrm{~mm}$ of bimodal pattern, which long rainy season that extends from June to September and a short rainy season from March to May and its average annual temperature is $12.7^{\circ} \mathrm{C}$.

\section{Study animals and design}

The study employed a cross sectional design using simple and systemic random sampling. The total sample size was calculated as per the formula given by Thrusfield [18] using 95\% confidence interval, 5\% desired absolute precision and with the assumption of $50 \%$ expected prevalence of ectoparasites accordingly a total of 423 sheep were included in this study. Five peasant associations (PAs) of the study district including Ambagiorgis, Ketema, Koseye, Kurajic, Sankatikim, and Sakbesak were randomly selected. The study animals were randomly selected using a systemic sampling technique from sheep population traditionally managed under extensive production system. Sheep of different age, sex, and body condition were included in this study. The animals were grouped into three age categories as young $(<1$ year), adult (1-3 years) and old ( $>3$ years) based on dentition. Animal body condition score on scale of $0-5$ was classified as starving, very thin, thin, moderate, fat and very fat on bases of criteria set by Ethiopian Sheep and Goats Productivity Improvement Program [3]. However, in this study sheep with animal body condition score less than 2 considered as poor; animal body condition score 2 and 3 were considered as medium and animals with body condition scores above 3 considered as good.

\section{Ectoparasites collection and identification}

Following proper restraining of the animals clinical examination was performed as described by Kumsa et al. [12]. The skin was palpated across all parts of the animal for the presence of parasites, and gross lesions suggestive of a clinical form of sheep ked and lice infestations and animals found infested were considered positive [12]. Visual inspection of the skin and wool were conducted to detect parasites. The parasite was removed carefully and gently by hand and forceps to avoid any damage on the body. The collected ked and lice from their attachment site inserted into universal bottles containing 70\% ethyl alcohol labeled with animals particularities and transported to University of Gondar (UOG) Faculty of Veterinary Medicine (FVM) Parasitology laboratory were further identification of the parasites were conducted under stereomicroscope according to the identification keys of Urquhart et al. and Wall and Shearer $[19,20]$.

\section{Statistical analysis}

Collected data were entered into Microsoft Excel 2003 spreadsheets (Microsoft Corp., Redmond, WA, USA) and analyzed using SPSS for Windows version 15.0 (SPSS Inc., Chicago, IL, USA). The animals were divided into different groups: according to their sex as female and male; age groups that is, as young ( $<1$ year), adult ( 1 to 3 years) and old ( $>3$ years) and body condition score was rated as poor, medium and good. Prevalence was determined based on the formula described by Thrusfield [18] as the rate of number of infested animals and total number of study animals. Associations between the explanatory variables (sex, age and body condition) and prevalence was evaluated by fisher's exact test analysis. Parameters recognized as significant in fisher's exact test analysis were then subjected to logistic regression analysis to investigate the associations between prevalence and explanatory variables. Differences were considered significant at value of $\mathrm{P}<0.05$.

\section{Results}

Out of 423 sheep examined 303 (71.6\%) were infested by M. ovinus,
B. ovis or both Table 1. The overall prevalence of M. ovinus and B. ovis was $33.57 \%$ and $12.07 \%$ respectively. In this study mixed infestation of (25.53\%) of M. ovinus and B. ovis was also recorded.

The common sites of M. ovinus infestation were the skin of neck, flank, shoulder, back, ramp and belly with the proportion of $57.21 \%$, $32.62 \%, 11.11 \%, 8.27 \%$, and $5.91 \%$ respectively. For B. ovis infested sheep, the commonly parasitized sites were neck (31.91\%), flank (29.55\%), back (16.8\%), shoulder (14.42\%), ramp (11.35\%) and belly (4.49\%) as shown in Figure 1.

The overall prevalence of $M$. ovinus and B. ovis based on sex, age, and body condition of the study animals is summarized in Table 2 . The overall prevalence of $M$. ovinus and $B$. ovis infestation in young ( $<1$ years), adult ( $1-3$ years) and old ( $>3$ years of age) sheep was $86.8 \%$, $67.5 \%$ and $46.1 \%$ respectively. It was observed that an overall prevalence of sheep ked and lice infestation was significantly $\left(\chi^{2}=56.52 ; \mathrm{P}<0.001\right)$ varied among the age categories of sheep. Logistic regression revealed that younger sheep was more likely to be infested with ked and lice than older sheep (OR=4.86; 95\% CI: 2.59-9.13).

The overall prevalence of sheep ked and lice in sheep with poor, medium and good body condition was $85.1 \%, 74.5 \%$ and $56 \%$ respectively. The study showed that the overall prevalence of the infestation was significantly $\left(\chi^{2}=22.52 ; \mathrm{P}=0.00\right)$ higher in poor $(85.1 \%)$ conditioned sheep than in good (56\%) body condition score group. Logistic regression revealed that sheep of poor body condition were more likely to be infested by ectoparasites compared to sheep of good body condition ( $\mathrm{OR}=4.36$; 95\% CI: 2.06-9.21). Furthermore, sheep of medium body condition were also more likely to be infested by ectoparasites compared to sheep of good body condition $(\mathrm{OR}=1.71$; 95\% CI: 1.01-2.88). Also, sex of sheep had a significant effects on overall prevalence of sheep ked and lice infestation $(\mathrm{P}<0.001)$.

Prevalence and summery of binary logistic regression analysis for $M$. ovinus on sheep based on explanatory variables were computed Table 3. The prevalence of $M$. ovinus was significantly $\left(\chi^{2}=99.26 ; \mathrm{P}=0.00\right)$ higher in young $(80.9 \%)$ and adult $(52.1 \%)$ sheep compared to old $(23.5 \%)$ sheep. The odds of the infestation of M. ovinus in young sheep were more times likely than in sheep of older age with $95 \% \mathrm{CI}=4.28-15.13$. Likewise, a significantly higher prevalence of $M$. ovinus in sheep with poor $70.1 \%(\mathrm{OR}=3.46, \mathrm{p}<0.001)$ and medium $64.5 \%(\mathrm{OR}=1.94, \mathrm{p}<0.05)$ body condition was recorded as compared to $40.5 \%$ in sheep with good body condition. Sheep with poor body condition were 3.46 times more at risk of infestation of $M$. ovinus than sheep with good body condition with 95\% CI=1.73-6.89. Higher prevalence of $M$. ovinus in rams than in ewes was recorded $(\mathrm{OR}=1.16, \mathrm{p}=0.05)$ however, it was not marginally significant among the sex groups of animals. Moreover, sheep with medium body condition were 1.94 times more at risk of infestation of M. ovinus than sheep with good body condition with $95 \% \mathrm{CI}=1.14-3.31$.

Prevalence and results of binary logistic regression analysis for $B$. ovis on sheep against explanatory variables were also computed Table 4 . Body condition had a significant effect on prevalence of $B$. ovis infestation of sheep $\left(\chi^{2}=16.56 ; \mathrm{P}=0.00\right)$ with $B$. ovis infestation being significantly higher in sheep with poor $(52.9 \%)$ body condition

\begin{tabular}{|c|c|c|}
\hline Ecto-parasites & No. positive & Prevalence (\%) \\
\hline M. ovinus & 142 & 33.57 \\
\hline B. ovis & 51 & 12.07 \\
\hline Mixed infestation & 108 & 25.53 \\
\hline Overall & 303 & 71.63 \\
\hline
\end{tabular}

Table 1: Overall prevalence of $M$. ovinus and $B$. ovis in sheep in the study area. 
Citation: Eshetu A, Ayele T, Mengistu S, Belina D (2017) Prevalence of Melophagus ovinus and Bovicola ovis infestation in sheep in Wogera District, North Gondar Zone, Ethiopia. J Vet Sci Technol 8: 440. doi: 10.4172/2157-7579.1000440

Page 3 of 5

\begin{tabular}{|c|c|c|c|c|c|c|c|c|}
\hline \multicolumn{2}{|c|}{ Risk factors } & Examined & Positive (\%) & $x^{2}$ & $\mathbf{p}$ & OR & $\mathbf{p}$ & $95 \% \mathrm{Cl}$ for $\mathrm{OR}$ \\
\hline \multirow{3}{*}{ Age } & Young & 204 & $177(86.8)$ & 56.52 & 0 & 4.86 & 0 & $2.59-9.13$ \\
\hline & Adult & 117 & $79(67.5)$ & & & 1.83 & 0 & $1.02-3.29$ \\
\hline & Old* $^{*}$ & 102 & $47(46.1)$ & & & 1 & & \\
\hline \multirow{2}{*}{ Sex } & Female* $^{*}$ & 279 & $183(65.6)$ & 14.71 & 0 & 1 & - & - \\
\hline & Male & 144 & $120(83.3)$ & & & 2.63 & 0 & $0.95-2.95$ \\
\hline \multirow{3}{*}{ Body condition } & Poor & 87 & $74(85.1)$ & 22.52 & 0 & 4.36 & 0 & $2.06-9.21$ \\
\hline & Medium & 220 & $164(74.5)$ & & & 1.71 & 0.046 & $1.01-2.88$ \\
\hline & Good* & 116 & $65(56)$ & & & 1 & - & - \\
\hline
\end{tabular}

OR: Odds Ratio; Cl: Confidence Interval; *: reference category

Table 2: Overall prevalence of $M$. ovinus and B. ovis according to sex, age and body condition of sheep.

\begin{tabular}{|c|c|c|c|c|c|c|c|c|}
\hline \multicolumn{2}{|c|}{ Risk factors } & Examined & Prevalence (\%) & $x^{2}$ & $p$ & OR & $p$ & $95 \% \mathrm{Cl}$ for OR \\
\hline \multirow{3}{*}{ Age } & Young & 204 & 80.9 & 99.26 & 0 & 8.05 & 0 & $4.28-15.13$ \\
\hline & Adult & 117 & 52.1 & & & 2.53 & 0.003 & $1.36-4.50$ \\
\hline & Old $^{*}$ & 102 & 23.5 & & & 1 & - & - \\
\hline \multirow{2}{*}{ Sex } & Female* & 279 & 50.9 & 22.83 & 0 & 1 & - & - \\
\hline & Male & 144 & 75 & & & 1.68 & 0.051 & $0.09-2.84$ \\
\hline \multirow{3}{*}{ Body condition } & Poor & 87 & 70.1 & 23.29 & 0 & 3.46 & 0 & $1.73-6.89$ \\
\hline & Medium & 220 & 64.5 & & & 1.94 & 0.015 & $1.14-3.31$ \\
\hline & Good $^{*}$ & 116 & 40.5 & & & 1 & - & - \\
\hline
\end{tabular}

OR: Odds Ratio; Cl: Confidence Interval; *: reference category

Table 3: Prevalence and results of binary logistic regression for $M$. ovinus on sheep based on age, sex and body condition.

\begin{tabular}{|c|c|c|c|c|c|c|c|c|}
\hline \multicolumn{2}{|c|}{ Risk factors } & Examined & Prevalence (\%) & $x^{2}$ & $p$ & OR & $p$ & $95 \% \mathrm{Cl}$ for $\mathrm{OR}$ \\
\hline \multirow{3}{*}{ Age } & Young & 204 & 41.2 & 3.37 & 0.18 & 1.21 & 0.53 & $0.67-2.17$ \\
\hline & Adult & 117 & 37.6 & & & 1.16 & 0.63 & $0.64-2.11$ \\
\hline & Old $^{*}$ & 102 & 30.4 & & & 1 & - & - \\
\hline \multirow{2}{*}{ Sex } & Female* $^{*}$ & 279 & 33 & 7.44 & 0.008 & 1 & - & - \\
\hline & Male & 144 & 46.5 & & & 1.83 & 0.009 & $1.17-2.87$ \\
\hline \multirow{3}{*}{ Body condition } & Poor & 87 & 52.9 & 16.56 & 0 & 3.49 & 0 & $1.89-6.44$ \\
\hline & Medium & 220 & 38.2 & & & 1.8 & 0.025 & $1.08-3.03$ \\
\hline & Good* $^{*}$ & 116 & 25 & & & 1 & - & - \\
\hline
\end{tabular}

OR: odds ratio; $\mathrm{Cl}$ : confidence interval; *: reference category

Table 4: Prevalence and results of binary logistic regression for $B$. ovis on sheep based on age, sex and body condition.

than in those with good (25\%) body condition and logistic regression analysis revealed that sheep with poor body condition were 3.49 times more likely to be infested by $B$. ovis compared to sheep with good body condition (OR=3.49, 95\% CI: 1.89-6.44). With regard to the effect of sex on the $B$. ovis infestation of it was observed that sex had a significant $\left(\chi^{2}=7.44 ; \mathrm{P}=0.008\right)$ influence on the prevalence of $B$. ovis where the prevalence of B. ovis was highest in rams (46.5\%) than in ewes (33\%). Additionally, logistic regression analysis pointed out that rams were more likely to be infested by B. ovis as compared to ewes (OR=1.83; $95 \%$ CI: 1.17-2.87). Prevalence of $B$. ovis infestation was highest in young (41.2\%) sheep 'compared to adult (37.6\%) and older (30.4\%) sheep but did not significantly vary among age categories $(\mathrm{P}>0.05)$.

\section{Discussion}

The result of the present study showed that the overall prevalence of B. ovis and M. ovinus infestation was high $(71.63 \%)$ in the sheep reared in extensive production system. This is in accordance with the reports of Kumsa et al., Desta et al., Seyoum et al. and Bekele et al. who reported high prevalence of ectoparasites in sheep and goats in different parts of Ethiopia, where prevalence as high as $81.5 \%$ [12,14,21,22]. This might be due to ideal climatic condition, poor husbandry practices, less awareness of the animal owners, minimal attention given to the ectoparasites and their effects on animals' health, and inadequate flock health program in the area $[12,14,16]$. B. ovis and M. ovinus might also

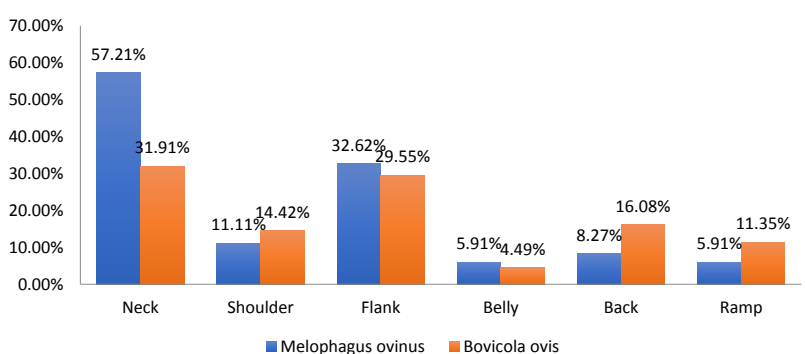

Figure 1: Common sites of Melophagus ovinus and Bovicola ovis infestations in sheep.

be unnoticed because of their small size but, can multiply before being discovered [11].

M. ovinus infestation and distribution is restricted to cooler highlands in hot and humid tropics, with temperature playing role in its dynamics [23]. In this context, M. ovinus infestation in sheep is reported to be prevalent in highland areas of Ethiopia [24]. The prevalence of $M$. ovinus in this study was $33.57 \%$ this is in accordance with the reports of Desta, Chanie et al. and Kumsa et al. who reported $36.5 \%, 32.99 \%$ and $31.7 \%$ in highland areas of Oromia and Ahmara regions of Ethiopia [12,14,16]. In contrast, the current 
finding also differs with the findings of some other studies, where lower overall prevalence of $M$. ovinus $9.2 \%$ [21] and $8.07 \%$ [22] were reported from different parts of the country. The prevalence of $M$. ovinus infestation up to $52.4 \%$ was also reported in highland area of Tigray region [25]. These differences might be due to variations in climatic condition, season of the studies and access to veterinary service in the study areas [12]. Moreover, these differences between current and earlier studies might also be due to the large differences in susceptibility to ked infestation between sheep breeds [26].

The prevalence of B. ovis (12.07\%) noted in this study is in agreement with $15.3 \%$ reported by Mulugeta et al. in Tigray region but it is lower than that of Kumsa et al. who reported a prevalence of $27.2 \%$ in Oromia region, $83.23 \%$ reported by Bekele et al. in central Ethiopia, $37.4 \%$ reported by Sertse and Wossene in eastern Amhara region, $47.86 \%$ and $34.43 \%$ reported by Chanie et al. in Yemenz Gera Midir and Kalu districts of Amhara region respectively and the prevalence of B. ovis $(12.07 \%)$ in this study is higher than $8.9 \%$ reported by Seyoum et al. in Sekela and $6.17 \%$ reported by Chanie et al in Bati district of Amhara region [12,16,17,21,22,25]. These differences in prevalence of B. ovis infestation of sheep might be due to dissimilarities in climatic conditions, animal husbandry and health care of sheep in the study areas [17].

Significantly $\left(\chi^{2}=56.52 ; P=0.00\right)$ varied differences in the overall prevalence of the ked and lice infestation on sheep between adult and young animals was observed and sex $\left(\chi^{2}=14.71 ; \mathrm{P}=0.00\right)$ and body condition score $\left(\chi^{2}=22.52 ; \mathrm{P}=0.00\right)$ of sheep had a significant effect on an overall prevalence of B. ovis and M. ovinus infestation in sheep. These findings agree with the reports of Mulugeta et al., Amare et al. and Kumsa et al $[12,15,25]$. It has also been reported that age differences in ectoparasite infestation is evident in sheep, where young animals are more susceptible to ectoparasite infestations, partly due to a higher proportion of accessible surface to body volume and poor grooming behavior of young animals [26,27]. The higher prevalence of ectoparasites in the poor body condition scores than good body condition scores could be due to lowered immune response as a predisposing factor and/or the poor body condition could be the result of chronic ectoparasite infestation [19].

The present study indicated that $M$. ovinus was prevalent in sheep accounting for $33.52 \%$ prevalence. Significantly higher prevalence of M. ovinus infestation $\left(\chi^{2}=23.29 ; \mathrm{P}=0.00\right)$ was observed in poor $(70.1 \%)$ and medium (64.5) compared to sheep of good body condition group (40.5\%). Logistic regression analysis indicated that poor body condition sheep were 3.46 times more at risk for $M$. ovinus infestation than those with good body condition $(\mathrm{OR}=3.46, \mathrm{p}=0.00)$. This is in accordance with the report of Kumsa et al. who reported that significantly higher prevalence of $M$. ovinus in sheep with poor (23.4\%) than good body condition (13.7\%) [12]. It has been reported that sheep in poor conditions suffer most from ked infestation and sheep ked have been reported to cause a reduction in carcass weight [23].

Furthermore, significantly $\left(\chi^{2}=99.26 ; \mathrm{P}=0.00\right)$ varied differences in the prevalence of the $M$. ovinus between age groups of sheep was also observed. The result of this study indicated that young sheep were more vulnerable to $M$. ovinus infestation than old animals. The odds of M. ovinus infestations in young sheep were 8.05 times compared to older sheep. The observation of significantly higher prevalence of $M$. ovinus in young than in old sheep is described by the movement of ked from ewe to lamb as an important source of infestation [12]. It has also been documented that, young animals are generally more susceptible to ectoparasites because of their immature immunity, a higher ratio of accessible surface to the body volume and poor grooming behavior [27]. Furthermore, logistic regression analysis revealed that sex of animals did not significantly affect the prevalence of $M$. ovinus infestation in sheep $(\mathrm{P}>0.05)$ which agrees with the findings of Kumsa et al. and Bekele et al. yet, the prevalence of M. ovinus infestation was higher in rams $(75 \%)$ than in ewes $(50.9 \%)[12,22]$.

B. ovis has tendency to move on body surface thus, can spread over the whole body causing considerable irritation, restlessness, interrupted feeding and loss of condition and is responsible for development of nodular hypersensitivity reaction lesions (cockle or 'ekek') in pickled pelts $[20,28]$. With regard to $B$. ovis infestation, significantly higher prevalence of $B$. ovis infestation $\left(\chi^{2}=16.56 ; \mathrm{P}=0.00\right)$ was observed in poor (52.9\%) and medium (38.2\%) compared to sheep of good body condition group (25\%). Poor body condition sheep were 3.49 times more at risk for B. ovis infestations than good body conditioned sheep. This is in agreement with the reports of Kumsa et al. and Amare et al. $[12,15]$. The higher prevalence of ectoparasites in the poor body condition scores than good body condition scores might be due to lowered immune response as a predisposing factor and/or the poor body condition could be the result of chronic ectoparasite infestation.

Furthermore, animals with poor condition and that are improperly feed and exposed to cold and debilitating diseases carry the heaviest infestations of lice, since debilitated animals do not groom themselves and leave the lice undisturbed [19]. Sex was significantly $\left(\chi^{2}=7.4\right.$; $\mathrm{P}=0.01$ ) associated with the prevalence of $B$. ovis in sheep where the prevalence was higher in rams (46.5\%) than in ewes (33\%). Logistic regression indicated that rams were 1.83 times more likely to harbor $B$. ovis than ewes. This might be due to the close contact the rams made with multiple ewes for longer time for mating during the breeding seasons which might increase the risk of acquiring lice from infected ewes as it has been reported that clinically affected and carrier animals are the sources of infection [29].

In the current study high $25.53 \%$ prevalence of concurrent infestation of $M$. ovinus and B. ovis in sheep was recorded. It was documented that the effects of ectoparasite infestations are more pronounced in heavy and mixed infestations [30-32]. Thus, this high dual infestation of $M$. ovinus and B. ovis in sheep in this study suggests that the effects of infestations were so pronounced on the animals.

\section{Conclusion}

This study concludes that the prevalence of M. ovinus and B. ovis in the study area is high with this high prevalence of M. ovinus and B. ovis infestation in the study area and considering effects of M. ovinus and B. ovis on health, welfare and productivity of sheep further studies on prevalence and economic impacts of infestation of sheep with $M$. ovinus and B. ovis are recommended. Furthermore, sanitation and hygiene of good standard of animal pens and houses are also recommended. To reduce and control $M$. ovine and B. ovis infestation appropriate flock health reprograms and control measures should also be implemented to improve the health and productivity of sheep.

\section{Acknowledgments}

The authors would like to thank University of Gondar (UOG), Faculty of Veterinary Medicine (FVM) Parasitology laboratory staffs for their kind support. We are also very gratefully to the animals' owners in the study area for their cooperation during the study. 
Citation: Eshetu A, Ayele T, Mengistu S, Belina D (2017) Prevalence of Melophagus ovinus and Bovicola ovis infestation in sheep in Wogera District, North Gondar Zone, Ethiopia. J Vet Sci Technol 8: 440. doi: 10.4172/2157-7579.1000440

\section{References}

1. CSA (2013) Livestock and livestock characteristics survey 2012-13 (private peasant holdings) Statistical bulletin no. 570, Addis Ababa, Ethiopia.

2. Mengesha M, Tsega W (2012) Indigenous sheep production in Ethiopia: A review Iranian. J Appl Anim Sci 2: 311-318.

3. ESGPIP (Ethiopian Sheep and Goats Productivity Improvement Program) (2009) Sheep breeds of Ethiopia: guide for identification and utilization. Technical Bulletin no.28.

4. Berhanu W, Negussie H, Alemu S, Mazengia H (2011) Assessment on major factors that cause skin rejection at Modjo export tannery, Ethiopia. Trop Anim Health Prod 43: 989-993.

5. James-Rugu NN, Jidayi S (2004) A survey of the ectoparasities of some livestock from some areas of Borno and Yobe States. Nigerian Vet J 25: 48-55.

6. Radostatits OM, Gray K, Hinchcliff H, Constable P (2007) A Textbook of the Disease of Cattle, Horses, Sheep, Pigs and Goats. 10th ed. WB Saunders, Edinburgh, UK.

7. Kebebew G (2015) Experimental study on sheep infested with $B$. ovis and $M$. ovinus of pathological changes, processed skin defect and effect of treatment in improving skin quality. MSc Thesis submitted to College of Veterinary Medicine and Agriculture, Addis Ababa University.

8. Phillips CJC (2005) The Effects of External Parasites and their Control on the Welfare of Livestock. Center for Animal Welfare and Ethics School of Veterinary Science, University of Queensland, p 63.

9. Petney TN, Kolonin GV, Robbins RG (2007) Southeast Asian ticks (Acari: Ixodida): a historical perspective. Parasitol Res 101: 201-205.

10. Colebrook E, Wall R (2004) Ectoparasites of livestock in Europe and the Mediterranean region. Vet Parasitol 120: 251-274.

11. (ESGPIP) Ethiopian Sheep and Goats Productivity Improvement Program (2010) Control of external parasites of sheep and goats. Technical Bulletin no. 41.

12. Kumsa B, Beyecha K, Geloye M (2012) Ectoparasites of sheep in three agroecological zones in central Oromia, Ethiopia. Onderstepoort J Vet Res 79: 1-7.

13. Kassa B (2006) Cockle, manage and pox: major threats to the leather industry in Ethiopia in Ethiopian Leather Industry: Prevalence towards Value Addition. Proceedings of the National Workshop, December 14-15, 2006, Addis Abeba, Ethiopia, pp 71-92

14. Desta TS (2004) Investigation on ectoparasites of small ruminants in selected sites of Amhara regional state and their impact on the tanning industry. MSc Thesis submitted to Faculty of Veterinary Medicine, Addis Ababa University.

15. Amare S, Asfaw Y, Tolossa YH (2013) Ectoparasites of sheep and goats in North-West Amhara Regional State, Ethiopia. Ethiopian Vet J 17: 55-67.

16. Chanie M, Negash T, Sirak A (2010) Ectoparasites are the major causes of various types of skin lesions in small ruminants in Ethiopia. Trop Anim Health Prod 42: 1103-1109.
17. Sertse T, Wossene A (2007) A study on ectoparasites of sheep and goats in eastern part of Amhara region, northeast Ethiopia. Small Ruminant Res 69 . $62-67$

18. Thrusfield M (2007) Veterinary Epidemiology. $3^{\text {rd }}$ ed. UK, Black well science, Wiley, New Jersey, USA, pp 178-197.

19. Urquhart GM, Armour J, Duncan AM, Jennings FW (1996) Veterinary Parasitology. $4^{\text {th }}$ ed. Blackwell Science, Glasgow, Scotland.

20. Wall R, Shearer D (2001) Veterinary External Parasites: Biology, Pathology and Control. $2^{\text {nd }}$ ed. Blackwell Science LTD, New Jersey, USA.

21. Seyoum Z, Tadesse T, Addisu A (2015) Ectoparasites Prevalence in Smal Ruminants in and around Sekela, Amhara Regional State, Northwest Ethiopia. J Vet Med 4: 2015

22. Bekele J, Tariku M, Abebe R (2011) External parasite infestation in smal ruminants in Wolmera district of Oromiya region, central Ethiopia. J Anim Vet Adv 4: 518-523.

23. Radostits OM, Blood DC, Gay CC (1994) Veterinary Medicine, Textbook of Cattle, Sheep, Pigs, Goats and Horses. 8th edn. Bailliere Tindall, UK, pp 1280-1308.

24. Kebede MC (2013) Effect of small ruminant ectoparasites in the tanning industry in Ethiopia: a review. J Anim Sci Adv 3: 424-430.

25. Mulugeta Y, Yacob HT, Ashenafi H (2010) Ectoparasites of small ruminants in three selected agro-ecological sites of Tigray Region, Ethiopia. Trop Anim Health Prod 42: 1219-1224.

26. James PJ (1999) Do sheep regulate the size of their mallophagan louse populations? Int J Parasitol 29: 869-875.

27. Lehman T (1993) Ectoparasites: Direct Impact on Host Fitness. Parasitol Today 9: 8-13.

28. Heath AC, Cooper SM, Cole DJ, Bishop DM (1995) Evidence for the role of the sheep-biting louse $B$. ovis in producing cockle, a sheep pelt defect. Vet Parasitol 59: 53-58.

29. Mekonnen S, Pegram RG, Gebre S, Mekonnen A, Jobre Y, et al. (2007) A synthesis of ixodid (Acari: Ixodidae) and argasid (Acari: Argasidae) ticks in Ethiopian and their possible roles in disease transmission. Ethiopian Vet J 11: 1-17.

30. Mohammad AN, Agbede IRS (1980) Control of ectoparasites of ruminants in Nigeria. In proceedings of the national seminar on the current problems facing the leader industry in Nigeria, NSCPFLIN'80, Nigeria

31. Singla LD (1995) A note on sub-clinical gastro-intestinal parasitism in sheep and goats in Ludhiana and Faridkot districts of Punjab. Indian Vet Med J 19 61-62.

32. Singh E, Kaur P, Singla LD, Bal MS (2017) Prevalence of gastrointestinal parasitism in small ruminants in western zone of Punjab, India. Vet world 10 $61-66$ 